\title{
Targeting economic development with science and technology parks and gateway cities: Schumpeterian possibilities of new developmental states in fostering local and global development
}

\author{
Mirando o desenvolvimento econômico com parques \\ científicos e tecnológicos e cidades gateway: \\ possibilidades schumpeterianas do novo desenvolvimentismo \\ na promoção do desenvolvimento local e global
}

\author{
PATRICIA ALENCAR SILVA MELLO* \\ MARIO GOMES SCHAPIRO** \\ NELSON MARCONI***
}

\begin{abstract}
RESUMO: Neste artigo, investigamos como ambientes inovadores, como política estratégica local, com características particulares do novo estado de desenvolvimento empresarial, associado ao que chamamos de política schumpeteriana, podem transformar regiões de países de renda média, como o Brasil. Em particular, procuramos responder à seguinte questão de pesquisa: como o Parque Tecnológico de São José dos Campos (STP-SJC) tem sido usado como uma ferramenta para promover o desenvolvimento regional? Para respondê-la, tendo como perspectiva um modelo lógico para essa política, focamos nos principais objetivos desse ambiente e empiricamente realizamos um estudo de caso aplicando a metodologia de rastreamento de processos.

PALAVRAS-CHAVE: Parque Tecnológico de São José dos Campos; ciência, tecnologia e inovação; rede global de produção; buzz local e pipelines globais; desenvolvimento.

ABSTRACT: In this paper, we investigate how innovative environments as a local strategic policy with particular features of the new entrepreneurial developmental state associated

\footnotetext{
* Supervisora de Pesquisa da Escola de Administração de Empresas de São Paulo da Fundação Getúlio org/0000-0003-3443-0271.

* Professor em regime tempo integral na Faculdade de Direito da Fundação Getulio Vargas, Rio de Janeiro/RJ, Brasil. E-mail: marioschapiro@fgv.br; ORCID: https://orcid.org/0000-0003-4136-4516.

*** Professor da Escola Escola de Administração de Empresas de São Paulo da Fundação Getulio Vargas - EAESP-FGV, São Paulo/SP, Brasil. E-mail: nelson.marconi@fgv.br. ORCID: https://orcid. org/0000-0002-1399-5305. Submetido: 25/July/2019; Approved: 9/October/2019.
} Vargas - EAESP-FGV, São Paulo/SP, Brasil. E-mail: patricia.mello@fgv.br; ORCID: https://orcid.
\end{abstract}


to what we call a Schumpeterian-style of policy can transform regions of middle-income countries, like Brazil. In particular, we sought to answer the following research question: how the São José dos Campos Science and Technology Park (STP-SJC) has been used as a tool to promote regional development? To answer it, having a logical model of this policy in perspective, we focus on this environment's main objectives and empirically we performed a case study applying process tracing methodology.

KEYWORDS: São José dos Campos Science and Technology Park; science, technology and innovation; global production network; local buzz and global pipelines; development.

JEL Classification: R11.

\section{INTRODUCTION}

While the world's attention is focused on the daily macro-decisions taken at the national level by several countries, regional public policies such as science and technological parks (STP) have been slightly exploited. These, although localized, aim at causing impacts that go beyond national barriers. They promise to recombine the accumulated local productive knowledge so that strategic connections are established with complex global production networks which, because prone to be spatially dispersed and organizationally fragmented, end up being shaped by this type of local policies.

Commonly observed in developed countries, over the past years, STPs have been gradually arisen in regions of middle-income countries, such as Brazil. Policy makers justify this option by arguing that this sort of innovative environment has the potential capacity to promote local development, such as: economic, innovative, academic, entrepreneurial, urban and social. Moreover, they expect them to serve as a privileged access to the global economy, connecting regions to global production networks, acting thus as what we call gateway cities - intermediate cities of emerging countries which potentially articulate these networks (Scholvin et al., 2017).

Conceptually speaking, STPs consist on a kind of innovative environment. Activities based on science, technology and innovation are carried out through synergistic and interactive actions of the so-called triple helix elements: (i) the entrepreneurial academia, producing knowledge; (ii) the academic productive sector with its laboratories and research centers to transform this knowledge into wealth; and (iii) the local government with the mission of promoting regional development in a new interconnected global context, through programs and incentives that create the appropriate urban space able to attract the right actors closer to this ecosystem (Mello, 2015).

What distinguishes a STP in the midst of other innovative environments is that they consist on an extensive real estate business. Previously projected, they count on a detailed urban planning and several studies of technical, financial and legal feasibility. Its mission would be to generate greater local complexity and consequent economic structural change, besides providing tactical couplings of its region into 
global production networks and an alternative global access to various local productive arrangements managed by these STPs (Mello, 2015).

According to STP logic model global aspects would be affected by this ecosystem. They would facilitate the positioning of their stakeholders and other regional actors in global production networks (GPNs), increase buzz, both local, through co-location and face-to-face, and global, by promoting events and partnerships with other countries. They would also work in GPNs, encouraging collective learning locally, in their R\&D centers and laboratories, and internationally, through their global pipeline policies (Tanner, 2005). This means that they have the potential to act as an intermediary point that connects the local network to the global economy and, consequently, they would catalyze gateway city functions in the region where they are located.

But, how can STPs as a local public policy really contribute to this broad development process specially of regions located at middle income countries like Brazil whose unfavorable macroeconomic context has constantly challenged its national development plan? What lessons can we learn with the São José dos Campos Science and Technology Park (STP-SJC), an apparent successful initiative of this kind in a way it may be transforming the region into a place likely to function as a gateway city of aerospace, defense and correlated sectors?

To answer this question we depart from new developmentalism studies which proclaims development as a result of economic sophistication and the incorporation of technical progress led by a new developmental state (Bresser-Pereira, 2016) and Schumpeterian's studies with its arguments of development process guided by innovative systems (Edquist, 1997; Lundvall, 1992; Nelson \& Rosenberg, 1993). Even though, we dare to advance this debate by focusing our attention to local government initiatives strategically designed to meet national action on the current globalized productive process. So we add to that theoretical perspective other intellectual analyses such as: studies exploring the development logic of a emerging network-economy dominated by many GPNs (Coe \& Yeung, 2015) and studies elucidating regional development by the local buzz and global pipelines effect and the formation of gateway cities (Aarstad et al., 2016; Bathelt et al., 2004; Scholvin et al., 2017).

This theoretical body aims to examine local context with larger analytical and spatial categories. Yet they have not been combined to elucidate empirical studies on the role that innovative environments like STP can play as a strategic policy in a new developmental state process. We need to dig into it to comprehend both local and global impacts these environments can cause, especially the ones located in less developed regions, in the current global interconnected economy where values are created, enhanced and captured by strategic global couplings.

In fact, the STP-SJC seems to represent an example of this new way of structuring local and global developmental policies. This investigation revealed this STP is responsible for the results the city is experiencing nowadays in terms of global development and of an important gateway city of specific sectors' configuration. Along the years, many institutions were created in the city to foster the aerospace sector. 
Starting in the 1950s when the Federal Government chose the São José dos Campos city to be transformed into an aerospace innovative hub. After that there were many other initiatives the most recently being the STP-SJC conception as a policy to promote development in a way it can face the prevailing global challenges.

It has been used by cities to be better integrated in GPNs, not only due to the global leaders' attractive effect and stakeholders' internationalization incentives, but also to the ability to foster the local buzz and global pipelines of the knowledge economy, the value capture stimuli and the ability to allow or not the access of other regions, actors and sectors to the global economy.

In order to deeply investigate this phenomenon, we performed a qualitative analysis, investigating documents, observing relations and interviewing 32 multiple players operating in and out this specific STP. We, then, performed a qualitative inquiry applying longitudinal case study' strategy and applied a process tracing method tracking five unities of analysis with Atlas-ti software support.

At the end we were able to confirm our thesis concluding that the STP-SJC is acting as a genuine gateway to various flows, integrating the access of regions of other middle-income countries to the aerospace and correlated sectors' global economy. Interviews confirmed that because of the 60 years of the aerospace industry history in São José dos Campos, recently redeemed and strengthened by the STP operation where the three global leaders develop today research and development: Boeing, Airbus and the national Embraer (this last one being itself a spin off of the city's innovative system), besides more than 350 selected stakeholders, the region was transformed into a vibrant innovative complex also used as an internationalization platform of many other actors.

The theoretical contribution of this paper consists on associating STP as a strategic local policy of the new developmental state to the consequent externalities on global production networks including a gateway city formation. It is structure in five different parts. First, we present the theoretical background, followed by our theoretical contribution and a methodological design where we contextualize the STP-SJC and the city trajectory to emphasize de case option. Then the major results are presented and discussed to finally conclude highlighting the major findings and future possible investigations.

\section{LITERATURE REVIEW}

In this section, we present and combine under the new developmentalism perspective different theoretical studies and their correlation with innovative environments: the global production network (GPN) approach, the regional development by the local buzz and global pipelines' effects and the formation of gateway cities. Our attempt was to mix them in a way we enlighten empirical policy analysis and infer the role innovative environments like STP can play as a strategic policy in the development process of middle-income countries. 


\section{Innovative environments and global production networks}

The rapid and profound changes experienced by the current global economy challenge the capacity of theorizing the world today. Organizationally fragmented and spatially dispersed production networks reflect the complex global scenario and its uneven results in terms of local development (Dicken, 2015).

One of the most recent theoretical proposals dealing with such phenomena is the global production network (GPN) approach. It highlights actors rather than products and regions instead of nations, criticizing Global Value Chain researches which encompasses sectorial and linear strategies, ignoring local institutional strategies. Not only actor's dynamics and strategies, but also their organization tendency in complex and synergistic organizational ecosystems would direct the formation and evolution of GPNs.

That is because innovative environments would encourage the connection between regional and global networks in a way that actors would locally capture values created and enhanced in those GPNs. These are considered strategic couplings seen as intentional and dependent on an active state intervention, and on embedded policies strategically tailored for this new global economic setting (Coe \& Yeung, 2015).

In fact, innovative environments are considered by this approach as an indigenous coupling, which contrary to the other ones, functional and structural, involves inside-out process and a more autonomous position in some GPNs (Coe \& Yeung, 2015). And this would be happening regardless of a macroeconomic adverse scenario in the national sphere cause local policies can be coupling to GPNs in the new fragmented globalization. Nevertheless, empirical studies have not shown that so far. Studies are needed to infer how such organizations, like STPs, have been used in this sense.

\section{Innovative environments and regional development}

Recent researches have spawned a wide variety of attempts to blend innovative environment insights with 'global' and 'local' perspectives on regional development. They identified a large number of clusters and agglomerations and explained that, although global economy is increasingly organized through global regions, a concentrated number of specialized agglomerations tied together through corporate networks of production and innovation stands out (Pike, Rodríguez-Pose \& Tomaney, 2011).

In this context several studies focus efforts on the local buzz and global pipelines aspects of innovative environments (Bathelt, Malmberg \& Maskell, 2004). According to them collaboration of firms in the same geographical region (local buzz) induces technological spillovers and value creation if these activities are combined with international collaboration (global pipelines), and vice versa (Aarstad, Kvitastein \& Jakobsen, 2016).

Local buzz refers to the idea that local connections in embedded contexts in- 
duce trust, reduce transaction costs, create technological spillovers, and provide more precise information and the sharing of combining ideas. Global pipelines, in contrast, bridges organizations internationally and facilitate the access to novel and non-superfluous information, which also foster technological spillovers and innovation (Aarstad et al., 2016).

This perspective requires policies to incorporate the "local $\mathrm{x}$ global" dilemma recognized by many as the "globalization paradox", which comes from the idea that the greater the ease of global knowledge exchange, the greater the reliance on local resources. In fact, the opposite processes of dissemination and concentration of knowledge reveals the success of innovative environments (Bathelt \& Glucker, 2011).

On one hand, innovative environments form internal networks (local buzzes) that require face-to-face relations, local atmosphere, personal encounters and the process of joint learning, but on the other hand, they identify and further global pipelines connections (Bathelt \& Glucker, 2011; Storper, 2013). The combination of these two dimensions potentiates the process of knowledge production and determines the performance of innovative environments (Bathelt et al., 2004).

Hence, the basis of localized innovative environments such as STPs lies in this process highly sensitive to geographical distance and proximity. Therefore, their local assets can become an advantage for regional development and to global connections by enhancing the region's articulation into GPNs (Coe \& Yeung, 2015). A better understand of such phenomena in an applied research is missing though.

\section{Innovative environments and gateway cities}

Since the late 1990s, cities have been considered nodal points in global commodity chains (Knox, 1997; Scholvin et al., 2017). Among them, global cities stand out as the top level of the global economy hierarchy and together they shape a world system of production control and market expansion (Friedmann \& Wolff, 1982).

The ones located in middle-income countries are considered to be gateway cities, whose function is to connect their respective regions of influence in the global economy. This term was first used by Burghardt in 1971. He defined them as an entrance and exit of some area. It suggests that gateway cities serve as a channel between their respective regions of influence and the outside world.

Scholvin et al. (2017) rescued this idea and inserted it in the current context of GPNs advancing studies that simply replicate global cities' functions into cities of emerging countries regardless of the particular context of such economies. They differentiate global from gateway cities not only considering the geographical location. They focus primarily on their ability to act strategically in the GPNs with a view to connecting globally the undeveloped regions of their influence in the global economy. This function of intermediation is what differentiates Scholvin's (2017) studies from others that also tried to investigate the global cities of the global south but did not enter into the intermediation function that they play (Parnreiter, 2010, 2015; Sigler, 2013). 
This effect is best apprehended by examining how cities and their strategic couplings in GPNs integrate the periphery with the global economy in a given network that begins in the global south countries, but which necessarily passes through the gateway cities. However, not only in one sector, but in many others by taking advantage of specific assets of a locally embedded sector, and by adding technological capabilities in a process of joint learning that reinforces positions in different GPNs. This is because innovation and knowledge generation that mark gateway cities are understood as cooperative processes that may involve local and non-local companies from different sectors. Together they seek to adapt existing technologies to local particularities or commercialize locally knowledge developed globally (Florida, 2011; Hospers, 2003). And the places where this knowledge is produced serve as intellectual articulations at different local and global scales (Scholvin et al., 2017).

Thus, it is necessary to examine middle-income countries' innovative environments, such as STPs, physically located in middle-income regions to observe how they strategically interact local networks with GPNs and thus operate towards a new developmental model.

\section{Associating the theoretical perspectives for a new developmental approach}

According to the literature above, in the current globalized world, characterized by organizationally dispersed and spatially fragmented production networks, cities stand out as a result of several actors' performance and policy implementation. Both this actors and policies would ensure, by performing strategic couplings in GPNs, the local and global capture of value generated and enhanced inside these cities (Coe, Dicken, \& Hess, 2008; Coe, Hess, Yeung, Dicken \& Henderson, 2004; Coe \& Yeung, 2015; Henderson, Dicken, Hess, Coe \& WaiChung Yeung, 2002). However, studies are still needed to investigate who these actors and what these strategic policies are, especially in the middle-income countries and especially in some of their cities that have gained prominence in certain GPNs.

As discussed above, studies recently arose seeking to understand the strategic role intermediary cities of middle-income countries can play by linking local regions to the global economy (Breul \& Revilla Diez, 2018; Scholvin et al., 2017). It happens since the current world is not only fragmented, dispersed, and structured in local and global networks of many actors and institutions. It is characterized by a productive knowledge economy, by economic complexity dictating the development process.

Physical innovative environments, such as STPs, is institutionally designed in a way leading companies are forced to be involved with their R\&D centers inside them. STPs would also export their local and regional companies, functioning as a channel through which various resources, like knowledge, pass by. Due to the degree of institutionalization they offer, the economic complexity they provide, the collective learning inter and intra sectors they foster, and the availability of talents 
and high quality research and teaching institutes available in there, they are able to capture values created and enhanced in both local and global networks they participate (Mello, 2015).

Even though it is true that cities, where these STPs are located previously counted on necessary conditions such as, the previous operation in a global chain of a sector embedded for a long time in the region, this fact seems not to be enough to transform cities into gateway cities. This is a path dependent process, meaning that the relational nature of regional development can constrain or promote future possibilities in a given region. Even if it counts on a previous successful history, it will still need to perform competences to absorb the existent capacities by means of capturing knowledge generated and cumulated locally (Cohen \& Levinthal, 1990; David, 2000; Freeman \& Soete, 1997).

In fact, whether the past trajectory enables successful connections in GPNs, this circumstance itself does not imply the subsequent couplings needed to sustain and improve the region conditions globally. This is especially true in such a global network economy, which increasingly requires technological complex capacitation and productive knowledge to maintain regions, as the gateway cities, in good positions in GPNs (Coe \& Yeung, 2015). And STPs have been used as a tool to address these exact purposes.

They aim at facilitating the more strategic positioning of its stakeholders and regional actors in GPNs, by enhancing both the local buzz through co-location and face-to-face relationships, and global pipelines by promoting international connections (Tanner, 2005). This means they would act as an intermediary point that connects the local network to the global economy, and consequently they would catalyze the gateway city function.

This article intends, therefore, to evolve in this discussion inserting STP in this new broader developmental theory by means of investigating the role they play in regional development process including a gateway city outcome. To do so, we consider STP both as an active player and a policy for strategic coupling for local and global development.

\section{METHODOLOGICAL DESIGN}

In order to answer our research question from the above literature perspective and in an attempt to theoretically contribute to them in connection to deeper development studies, we chose The Science and Technology Park of São José dos Campos (STP). Many motives lie behind this choice, among them:

STPs have been fostered since 2000 by Brazilian policies as a way to promote local and global strategic development. It was understood that although the country is increasing its scientific publications and, thus, outstanding in knowledge production, this is not being transformed into development because of the non synergistic interaction with the productive sector (Steiner \& Robazzi, 2008). Thus, 
to correct such system failure, physical innovative spaces were stimulated to proximate the so-called elements of the triple helix ${ }^{1}$.

São José dos Campos has a history of more than 70 years of innovative culture initially transplanted by the Massachusetts Institute of Technology - MIT from which the Technical Aerospace Center (CTA) was derived. It includes the Technical Institute of Aeronautics (ITA) and the Companhia Brasileira de Aeronáutica S/A Embraer spinoffed in the 1950s and 1960s.

The aerospace sector is one of the most important segment of the advanced economies' productive structure due to its technological sensitiveness. Intensive in technology industries this sector needs high investments in R\&D. Their products involve highly complex integrated systems with continuous and incremental incorporation of technological innovations from other industries. Also, the high requirements imposed by the aerospace industry allow a high level of technological innovation diffusion to other sectors of the economy, but it requires an elevated degree of technical standards. It tends to be organized in a concentrate oligopoly in global level, despite efforts to strengthen national conglomerates competitively. The state is the great coordinating agent of the aerospace industry, not only in sectors where it controls directly, such as military and space, but also in the commercial segments. Governmental policies for the aeronautical industry are responsible for the historical innovation and increase competitiveness of most developed countries (Rosenberg, 2006; Turkina, Assche \& Kali, 2016).

Indeed, several state strategic decisions surrounded the São José dos Campos' trajectory. The Federal Government was responsible for choosing this city to receive that national aerospace institutional design in the 1950's. It was also the Federal Government who formulated the first policy to foster STPs in Brazil in 2002. The federal state of São Paulo, inspired by this federal policy, created the first regional state policy called the São Paulo System of Technology Parks, and also chose, in 2006, São José dos Campos to be one of the five cities to benefit financially and technically with this program. In fact, this city was the first to meet a range of requirements imposed, at which time it ended up pioneeringly certified by the program. Finally the STP was juridically and institutionally constituted according to objectives designed in municipal programs that financially support it until now;

The STP shows very promising results and a significant volume of investments. Is the house of the three largest aerospace companies in the world, including the national Embraer. It also deals with almost than 400 stakeholders, including large and small companies, national and international, from different sectors. Besides the STP manages nowadays the Aerospace Local Productive Arrangement and another cluster related to information technology and communication.

It is also considered as an ideal model to be replicated in other regions, reason

\footnotetext{
${ }^{1}$ Concept presented by Etzkowitz and Leydesdorff in 1995, borrowing from biology the concept of "double helix" of DNA. It assumes innovation process depend on the interaction of Government, Productive Sector and Academia (Etzkowitz \& Zhou, 2017; Leydesdorff \& Meyer, 2003).
} 
why the current institution that manages the STP has been called to present guidelines to implement other STPs in Brazil and to formulate future public policies that intend to disseminate innovative environments.

Based on this reasoning we understood this STP experience could reveal us recurrent patterns of a new developmental state focused on strategic couplings grounded on local and global development stratagems and on a formation of a gateway city in the aerospace and correlated sectors' GPN.

Table 1: Data Collected

\begin{tabular}{|c|c|c|c|}
\hline Data Sources & Description & Period & Role \\
\hline $\begin{array}{l}\text { STP official } \\
\text { documents }\end{array}$ & $\begin{array}{l}16 \text { documents (contracts, } \\
\text { institution's statute, other } \\
\text { documents) }\end{array}$ & $\begin{array}{l}\text { January } 2006 \\
\text { to } 2018 .\end{array}$ & $\begin{array}{l}\text { Source of additive } \\
\text { data coded. }\end{array}$ \\
\hline Interviews & $\begin{array}{l}32 \text { in-depth interviews: } \\
\text { * Large companies: } 8 \\
\text { *Small companies: } 6 \\
\text { *APL: } 3 \\
\text { *Incubator: } 1 \\
{ }^{*} \text { State institution: } 1 \\
{ }^{*} \text { Academia: } 4 \\
{ }^{*} \text { STP developers: } 3 \\
{ }^{*} \text { State: } 3 \\
{ }^{*} \text { STP : } 3\end{array}$ & May to July 2018 & $\begin{array}{l}\text { Important for } \\
\text { building the } \\
\text { history of the STP } \\
\text { formation and the } \\
\text { way it has been } \\
\text { capturing value. }\end{array}$ \\
\hline $\begin{array}{l}\text { Participant } \\
\text { observation }\end{array}$ & $\begin{array}{l}\text { Field notes of the } \\
\text { day-by-day STP operation. }\end{array}$ & May to July 2018 & $\begin{array}{l}\text { Necessary to } \\
\text { comprehend the } \\
\text { dynamics inside } \\
\text { the STP. }\end{array}$ \\
\hline $\begin{array}{l}\text { Public } \\
\text { documents }\end{array}$ & $\begin{array}{l}\text { News, websites, } \\
\text { articles, etc. }\end{array}$ & May to July 2018 & $\begin{array}{l}\text { These documents } \\
\text { completed the } \\
\text { information on the } \\
\text { STP action. }\end{array}$ \\
\hline
\end{tabular}

Elaborated by the authors.

In order to carry out this analysis we use the qualitative method called process tracing, or process mapping. This is the most indicated method when causal inferences are sought in an in-depth study of a single case. It relies on evidences arising from a causal mechanism that provokes a result about which the researcher is interested. Through it we examined whether the incorporation or not of a new developmental and Schumpeterian strategy, explains the result that the policy has been achieving in terms of better connections in GPNs caused by a regional innovative policy to promote a broad development of regions located in middle-income econ- 
omies in a way the region is transformed into a gateway city (Bennett \& Checkel, 2015; Venneson, 2008).

Our first step was to identify actors and groups of actors both inside and outside the STP. Initially we thought on exploring only the aerospace sector following studies on chain tendency, but soon we realized that the STP differential in transforming the city's economy relies on its ability to capture value from different sectors, to add productive capacity and in a joint learning process to generate development in science, technology and innovation in a cross-sector way. We decided to interview enterprises from different sectors and to investigate the STP in all its operation. We tried to interview representatives of the triple helice's studies: government, productive sector and academia. All of them were recorded but kept anonymous.

The analysis involved initial data exploration and the identification of unities of investigation in Atlas-ti. representing particular variables able to explain what is behind the local and global impact caused by STP-SJC. We tried to sort what was the most relevant patterns for the outcome investigated by performing an inductive coding and information labeling. This step was then followed by a tracking of motives supporting each unity of analysis.

Table 2: Unities of analysis

\begin{tabular}{|l|l|l|}
\hline AXIS & \multicolumn{1}{|c|}{ RESULTS } & \multicolumn{1}{c|}{ PROCESSTRACING } \\
\hline 1 & $\begin{array}{l}\text { From state strategies and } \\
\text { institutions to a new model of } \\
\text { policy for development. }\end{array}$ & $\begin{array}{l}\text { How state strategies, the creation of governmental } \\
\text { institutions over the years in the city, the national } \\
\text { global leading company (Embraer), and the Local } \\
\text { Productive Arrangements were necessary but not } \\
\text { enough to determine value capture regionally and } \\
\text { the consequent gateway city consolidation by the } \\
\text { STP ? }\end{array}$ \\
\hline 2 & $\begin{array}{l}\text { The action of international lea- } \\
\text { ding companies. }\end{array}$ & $\begin{array}{l}\text { How international leading companies attracted by } \\
\text { the STP to the city operate in a way to conform the } \\
\text { gateway city materialization? }\end{array}$ \\
\hline 3 & $\begin{array}{l}\text { The national small and medium } \\
\text { size technology enterprises. }\end{array}$ & $\begin{array}{l}\text { How the STP support to their small and medium size } \\
\text { technology enterprises contributes to the gateway } \\
\text { city formation? }\end{array}$ \\
\hline 4 & $\begin{array}{l}\text { The super cluster formation } \\
\text { and sector diversification. }\end{array}$ & $\begin{array}{l}\text { How the sector's diversification promoted by the } \\
\text { STP by means of adding technology capacities to } \\
\text { the aerospace segment benefits the gateway city } \\
\text { characteristic? }\end{array}$ \\
\hline 5 & $\begin{array}{l}\text { The inclusion of regions and } \\
\text { other actors into many GPNs. }\end{array}$ & $\begin{array}{l}\text { How other regions and actors access the global } \\
\text { economy through the STP? }\end{array}$ \\
\hline
\end{tabular}

Elaborated by the authors.

Finally, this study follows high rigor criteria of credibility, constructed mainly over interview recorded and public documents. It is also based on transferability, 
dependability and confirmability features, since it can be replicated in other places or reapplied following the same methodology herein designed.

\section{MAIN RESULTS}

To better organize the data collected to comprehend if, why and how STP is influencing a new pattern of development in the São José dos Campos city we propose causal mechanisms investigative processes. This is a method that scans the intermediate steps in the cognitive mental process that leads the actors to make specific decisions, and makes inferences about the hypotheses of how this process was established and whether and how it could have generated the expected results (Bennett \& Checkel, 2015).

This method makes use of history, of documents, of interviews and of other sources to observe if the causal process is evidenced in fact in the sequence and values of the variables that intervene in the process. It performs the analysis of existing evidence in processes, sequences and conjunctures of events occurred in a case. Its purpose is to develop or test hypotheses on causal mechanisms that could explain the case (Bennett \& Checkel, 2015).

\section{STP as sufficient condition}

Previous institutions and the embedded aerospace 70 years history were necessary conditions for the STP to be created. Without them this new initiative would have not been feasible, but they by themselves were not enough for the gateway city configuration.

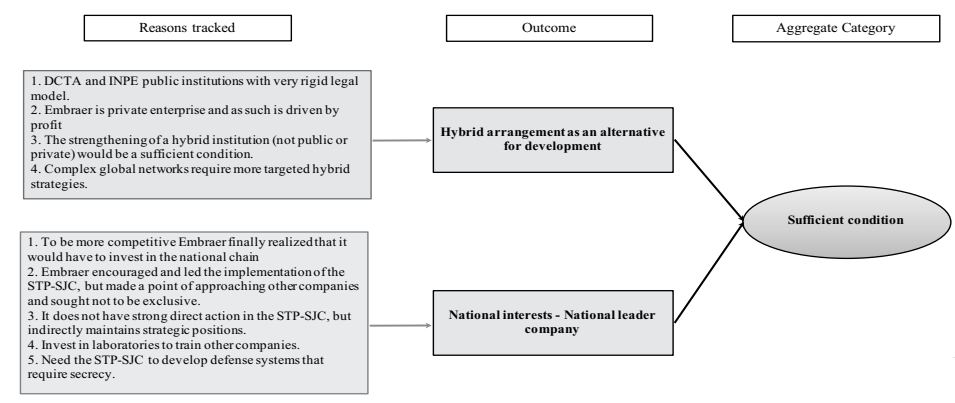

"Embraer and CTA have their value but their action is limited. They employ people and generate revenues for the city, but STP acts beyond that. It represents continuity and also opportunities opening caused by the environment it creates, for instance, the universities and talents it form and retain locally"2.

\footnotetext{
${ }^{2}$ A representative of a company located outside the STP, but in the city. It operates with different information technologies most of them directed to space and defense IT solutions.
} 
Some other interviewees also stated "[...]contrary to other institutions, it [STP] is the only one concerned with capturing values in the city." ${ }^{3}$ Among these other players we could identify some, like:

The Department of Aerospacial Science and Technology (DCTA) and the National Institute for Space Research (INPE): interviewees claimed because of their government structure they are not flexible as the STP is. They don't have the private perspective to solve technological problem. "Not even Embraer uses it anymore, other entities even less. People cannot access these places..."4. Although the importance they had over the years to form a technological culture in the city, they are not able to deal with all demands of the current global interconnected economy.

The national global leading company, Embraer and all its national suppliers from the aero APL - if the first institutions above are too public to deal with the nowadays global demands, this other companies are too private to capture value and focus on promoting local development. "Clusters and APLs are not concerned with capturing values. They have business vision. They focus on what is more profitable for them"s. Thus, a flexible institution, like STP, is crucial to return to the city the public investments made over the years, besides the jobs created by Embraer, because "the whole city would be held hostage to the financial situation of this company".

Embraer also recognize during the interviews that it depends on the STP to be more competitive. Indeed it was one of the main responsible for the creation of the STP. It has many different companies there created in the last years, a R\&D center and the Research Laboratory for Light Structures (LEL) which serves many different sectors. And Embraer keeps inside the STP its whole defense and security systems' operation, which couldn't be developed inside its huge fabric district for safety reasons. Besides it promotes training, workshops, helps to rise public funding, invest on start-ups and is trying to use the STP to better capacitate its suppliers to innovate. "We never thought on a gateway function, but we had this rationale always in mind and that is why the STP is capable of implementing in the city programs we never did before" ${ }^{7}$.

In fact, even though some complaints regarding the way more or less political the STP acts or some accusation on its inclination toward some players' protection the benefits derived from its hybrid nature and the consequent ability to configure a gateway city transformation, which the region never experienced before, are uncontroversial in all interviewees' reports. According to them, this is due to the cooperative environment full of students, small, medium and big size companies,

\footnotetext{
${ }^{3}$ Report provided by the director responsible for administrating the APLs.

${ }^{4}$ Information given by the STP directory.

${ }^{5}$ Says people from the STP responsible for coordinating the APL.

${ }^{6}$ This was the report of interview that operates inside Embraer.

${ }^{7}$ This was the report of interview that operates inside Embraer.
} 
and also because of the above institutions that in a way or another also operate there together with other similar institutions from other regions, such as the Technological Research Institute (IPT) from São Paulo and the National Disaster Operation Centre (CEMADEN) that moved its whole operation together with its 200 employees to the $\mathrm{STP}^{8}$.

\section{The STP power to attract international players to the gateway city}

STP attracts leading global companies and other international players encouraging them to bring their R\&D centers and to cooperate with other stakeholders residing in the STP.

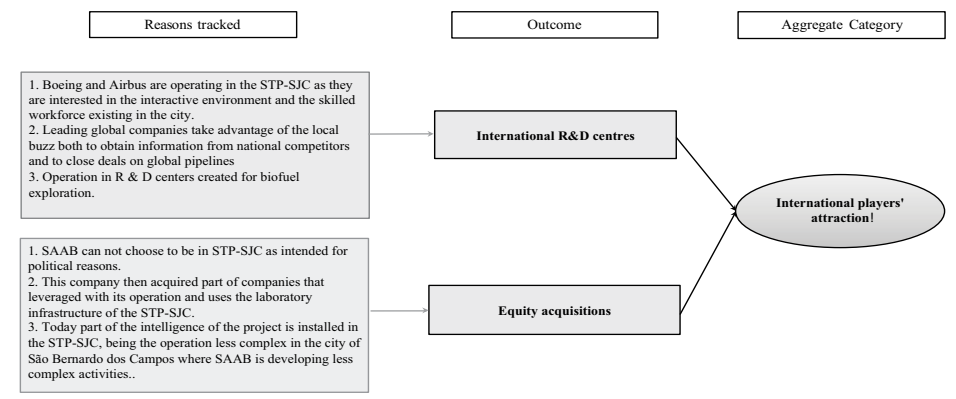

"The STP is the one who attracts them [leading global companies] not the APLs. Boeing and Airbus could operate in the APL without moving its R\&D operation to Brazil. They were interested on coming because of the connections the STP promotes and the talents the it retains there" 9 .

In fact, the three largest companies in the aerospace sector, including Embraer are there and do not intend to move out:

The American Boeing could not record interview because of the new enterprise under construction with Embraer, but it operates for a long time inside the STP in the Joint Research for Biofuels created there. There were many comments on this company operation in the STP by the interviewees. Mostly they consider this company to be interested on learning interactively and to access the innovation process under course in the STP.

The European Airbus, that although closing many important operations in Brazil, due to the biggest economic crisis Brazil faces and that hit in particular some of its partners, decided to keep its office in the STP. Representatives of this company confided that because of its relevance, and the capacity to establish networks everyday the company would not leave this place.

Besides those, an interesting information gathered in this research regards the

\footnotetext{
${ }^{8}$ More information on the STP website: http://www.pqtec.org.br/quem-esta-aqui/instituicoes-de-cienciatecnologia-e-inovacao. Visited on July 22, 2018.

${ }^{9}$ Say people from the STP responsible for coordinating the APL.
} 
Swedish company: SAAB. It moved to Brazil to construct the fighter aircraft after winning an international bid over Boeing and Airbus. Political reasons make SAAB to open its fabric in another city (São Bernardo do Campo), but their R\&D center and all its intelligence is in the STP. This is because this company bought a national company (Akaer), which transferred its whole operation to a huge lab existent in the STP. So, the less complex operation is in São Bernardo do Campo, but the technological intelligence is in the STP.

There are other international big companies also composing the group of global leading enterprises presented there, like Ericsson. This is also a Swedish company, one of the leading providers of Information and Communication Technology (ICT) to service providers, that opened an R\&D center for ICT in the STP. Representatives of this company stated that it was contracted by the São José dos Campos municipality to come up with solutions regarding smart cities. This initiative was so successful that many other cities want to contract the STP to replicate the same technological solutions, focused on safety, mobility and digital interactions.

\section{STP capacitates and internationalizes national small and median-size enterprises}

STP encourages their resident companies to internationalize their operation and gives the support to better position them in GPNs, including the Embraer supply chain. Many interviewees stated that although the design authority that Embraer holds which gives it, besides other advantages, the power to choose its own suppliers, $80 \%$ of its aircrafts are composed by import components. The most sophisticated part of this chain is occupied by international companies and the STP believes it is its duty to change this situation by capacitating and make more internationally competitive the aero APL.

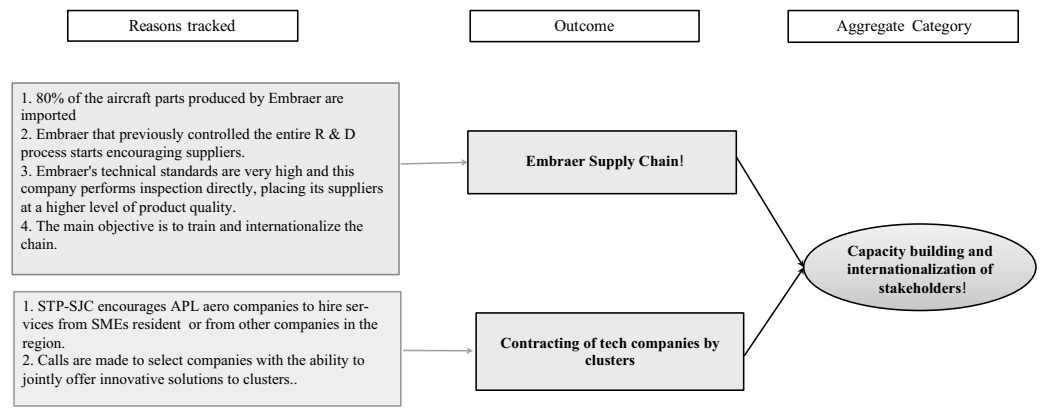

"The STP responsibility is to help companies to internationalize, to transform this cultural position to be waiting for the government to provide everything, to develop a new market vision"10.

${ }^{10}$ Information given by the STP directory. 
The STP also stimulate the aero APL's industries to contract services from its residents. Because of many interactions small resident companies have opportunities to come up collectively with new technological solutions. For instance, representative of a medium-size company of the aero APL stated that because of the STP intervention it contracted some small companies to develop different digital services, which helped the company to make a wide use of 3D design software integrating management and the industrial infrastructure.

"These services would not be contract by a APL industry if it weren't for the STP's EBTs. These same solutions can be developed by big companies, but it is too costly for us ${ }^{11}$ ".

On the other side, although some SMEs complaints on concerning the not enough help provided by Embraer and the Government, they realize the STP positive effect on their business capacitation to close big contracts, including the internationalization of their operation.

\section{STP diversifies aerospace technological applications and incentivize economic complexity}

Another evidence of the STP's capacity to capture values and upgrade the whole city is its competence to be structured as a super cluster, which derives from one specific sector, but by adding technological capacities, it operates in transversal way, involving different sectors.

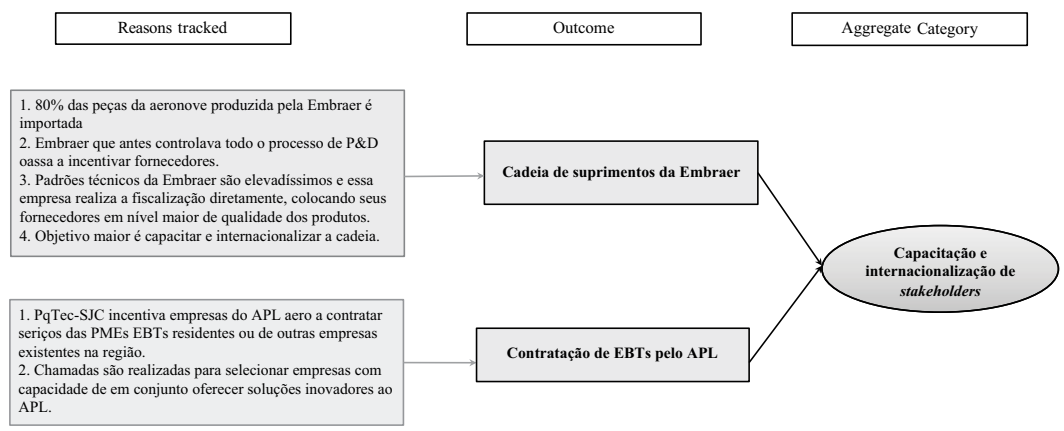

"To be a gateway city its STP has to open the door for all technologies and foster new ones. It cannot be limited to one sector. It has to focus on an innovative development model. It has also to form an intelligence nucleus and consider it a national strategy to guarantee development through technology not through a single sector" ${ }^{12}$.

In fact, economic complexity has been in recent years an outstanding indicator in the city of São José dos Campos. Compared to the group of municipalities that are

\footnotetext{
${ }^{11}$ Report from a representative of medium-size enterprise of the aero APL located outside the STP .

${ }^{12}$ A STP counselor gave shared this insight.
} 
part of the same region and the others that are also under the influence of some STP, the city of São José dos Campos stands out in the index of economic competitiveness:

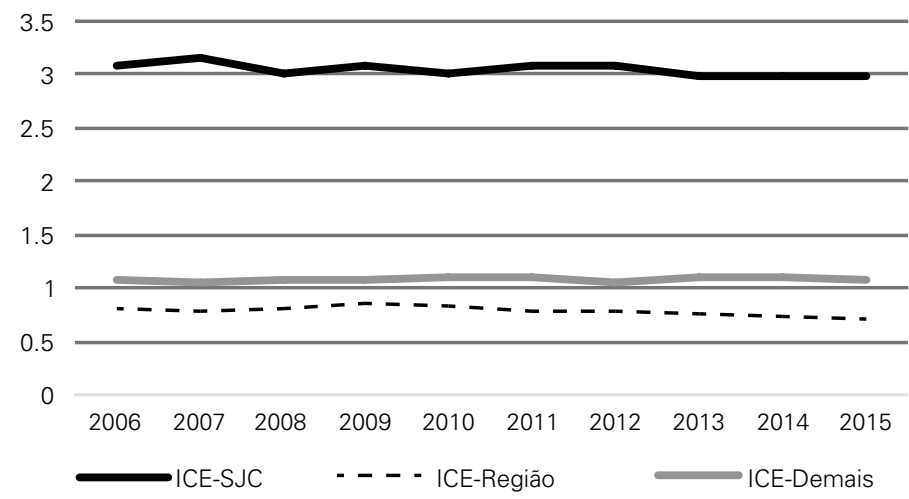

Thus, the STP fosters economic complexity and technological capacity additions to retains it in the city:

"The STP influences this gateway city effect only because we facilitate and promote the flow of many technological knowledge but not in only one sector. It happens because we are opened to any area that using our aerospace expertise, add other technical capabilities to different sector" ${ }^{13}$.

Embraer states it always incentivized diversification so as to the STP follow its own destiny and not to be under this sector control.

"We were aware we had to assume a role not as the protagonist of the STP so we always incentivize diversification. The main example was the creation of our first lab, LEL. It can attend any sector with complex structures requiring light materials, like the automotive and oil and gas sectors" ${ }^{14}$.

The STP representatives insist they are not to be specialized in one segment. They prioritize the knowledge development, how to retain it and how to apply it. This knowledge can be created, developed in one specific sector, but its application can vary and it is the STP responsibility to apply them in any sector transversally. This can generate development to many sectors including the aerospace one itself.

\section{STP opens the gate to other actors and regions}

All companies from the APLs with headquarters outside São José dos Campos have to pass by the STP to be certified, better trained and to make connections locally and globally. Other APLs are being created in other regions, also encouraged by the STP. They are being called sub APLs. But they will always depend on the STP in

\footnotetext{
${ }^{13}$ Information given by the STP directory.

14 This was the report of interview that operates inside Embraer.
} 
some degree because the R\&D centers and labs are there, as well as, programs, workshops and preparation to fulfill the high level of global safety standards in this sector.

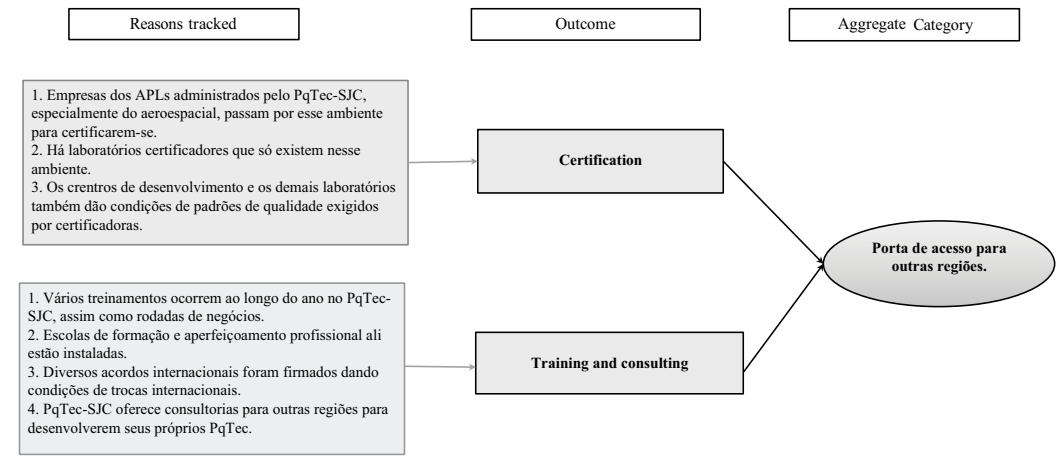

Besides that the STP operates in many other regions providing STPs implantation services counseling. They are being contracted by many Brazilian regions because they are seen as a development policy model.

"The STP is extending its influence in the region. We are participating in many bids to run different STPs. As Financial Times recognizes SJC is the center irradiator of opportunities and we have a great deal to do with this result" ${ }^{15}$.

Finally, the STP is signing an agreement with European Union to serve as a soft land of any European company willing to operate in Brazil. They occupy an office there with low cost and learn everything they need to decide to really open their operation in Brazil. By doing this the STP will also encourage partnerships with its residents and provide a way for them to internationalize their operation in Europe.

\section{DISCUSSION}

The middle-income countries catching up process seems to rely on several institutional tools and specific public policies so as to cope with the international economic challenges which changes overtime. In Brazil, and in the São José dos Campos city in particular, different strategies applied over time demonstrate this rationale. Since it was chosen by the Federal Government to develop a national strategic sector, São José dos Campos has been adapting its policies and entities in order to survive in the global reality presented.

Its most important company, Embraer, was a state-owned company by the time the country put great emphasis in import substitution policies, in a process known as the "Big Push" of the industrialization process. This was also the time when government institutions such as CTA and INPE were created. Internationally it was

${ }^{15}$ Information given by the STP directory. 
an era of a nationalist world, with few global interactions where a mass production process, known as Fordism, reigned. In fact, even though the global intrinsic characteristic of the aerospace sector, Coe and Yeung (2015) remember this was a time of the TNCs tendency to self-contained their multi-domestic structures merely replicating abroad their home operations (Coe \& Yeung, 2015).

Later on, in the 1980s, Brazil experienced a long period of stagnation and inflationary crisis followed by criticism of intense state intervention in Latin America and had to redesign a new economic and structural policy based on the so-called Washington Consensus. The result was economic reforms aimed at privatization programs and Embraer in 1992 was part of it. It was included in the privatization program and sold to a consortium of banks and pension funds. The world, much more competitive, forced the company to change its focus from political to more administrative and financial private efficiency, even though most part of Embraer success would still be dependent on the many government technological order for military purposes, which resulted in the creation of sophisticated aircrafts, such as "Tucano" and "Super Tucano".

This company, perhaps because of its global operation, was also able to foreseen a new global organization much more dispersed and fragmented, where global leading companies would controlled several complex production networks fostered by various strategic policies (Coe \& Yeung, 2015). This new scenario demanded from the emerging economies a new developmental model with more coordination induced by the state in partnership with the private sector. Now a more inductive role was required and public policies directed to strategic development were supposed to be designed.

Those were the reasons why Embraer actively participated in the STP project, but it did not assume a protagonist role. It induced the government to diversify sectors, its first effort was to construct a complex lab to come up with innovative solutions regarding light structures, not only to be used in the aerospace sector, but to be also applied in any other fields that requires complex light structures.

STP as a hybrid organization had not served only Embraer interests. It attracted its biggest competitors and induced them to implant their R\&D centers and to transfer to talents graduated there the technology created. It also gives the support it can to internationalize its stakeholders, training them to better fulfill with the highest international standards, organizing various events which enables partnerships of various level, fostering an environment where people co-locate and collective learn locally and globally in a super cluster. Because of the international initiatives it also fosters global pipelines and are managing to enable actors and regions from other parts of Brazil to access the complex global economy.

These features, anchored in a territorial embedded sectorial history and based on the power not only of Embraer, but also of national, regional and local governments and of many talents the city has formed over the years in ITA, are determining the way STP activate the gateway city function in São José dos Campos. It is preparing the city to operate in the current global world, capturing values created and enhanced and fostering productive knowledge. 
Companies willing to come to Brazil to operate in the aerospace and correlated sectors are naturally attracted by its many features: institutionalization that minimize the Brazilian institutional deficiencies, talents, synergies among many players, training and certification programs, besides the APLs' administration. All these together and the potential of this model to be replicated over Brazil and the gate to be open to the global economy confirm studies on GPN, regional development and gateway cities, highlighting new strategies for policies and development.

\section{FINAL REMARKS}

Even though the São José dos Campos' journey of decades investing in the aerospace field and the fact that this city hosts, in consequence, its third-largest aerospace company, as a MIT spin-off that also affected the creation of other successful home institutions, such as CTA, ITA and INPE, only recently the city managed to institutionally capture in the region values created and enhanced over the years and therefore to occupy a prominent position in relevant GPNs.

The city's nomination for the Aerospace City of the Future by the fDI Intelligence for the first time can be seen as an evidence of this novelty. It happened only after the city conceived a new local, innovative and hybrid institutional model, designed to promote local and global development in a highly interconnected world: the SJC-STP.

If the city's high investment in one sector taught us how to become part of the global economy, the SJC-STP taught that in today's complex and networked global economy it is also possible to regionally retain sector's value by holding in the region a synergistic-type of environment. The one capable of offering technologically innovative solutions and to add capacities to different sectors in a cross-fertilizing ecosystem, while combines academic, entrepreneurial and government interests.

These are the main conclusions the longitudinal case study developed in this paper revealed. It sought to understand causes this STP count on to influence the transformation of São José dos Campos into a gateway city of aerospace, defence and correlated sectors. This was possible after combining three theoretical approaches' perspectives, adding it to the new developmental and Schumpterian studies. They understood the importance of innovative environments in shaping cities: GPN, regional studies and gateway city's studies. But was never combined and applied in a middle-income innovative regional policy.

The theoretical contribution of this investigation regards thus the association of these three fields of studies with the rationale of new developmental theories and the reasoning of STPs as a policy for local and global development. Our effort was to allow an interchange between these theoretical approaches by presenting and analysing the implementation process of a specific case study.

We accomplished that although it is too early to measure all impacts since it is reasonable to conclude that the SJC-STP is playing a strategic role in a new 
globalized scenario and as consequence transforming the region into a gateway city. This result depended on previous necessary conditions the city developed over the years, but without the STP the current couplings into different GPNs would not be possible.

It happened not only because of the territorial embeddedness and the power the STP has to attract international companies with their R\&D centers and to export its own stakeholders, retaining in its region values created and enhanced, but also because the SJC-STP is being able to open the gateway city to other actors and regions to access the global economy.

Future studies would be important to isolate the STP economic performance and perhaps to compare these results with other STP's experiences in middleincome countries like Brazil which, to be internationally competitive, demands particular policies, cities strategic configuration and localized and innovative institutions.

\section{REFERENCES}

Aarstad, J., Kvitastein, O. A., \& Jakobsen, S. E. (2016). Local buzz, global pipelines, or simply too much buzz? A critical study. Geoforum, 75, 129-133. https://doi.org/10.1016/j.geoforum.2016.07.009

Bathelt, H., Feldman, M., \& Kogler, D. (2011). Beyond Territory (1st ed.). New York: Routledge.

Bathelt, H., Malmberg, A., \& Maskell, P. (2004). Clusters and knowledge: Local buzz, global pipelines and the process of knowledge creation. Progress in Human Geography, 28(1), 31-56. https://doi. org/10.1191/0309132504ph469oa

Bennett, A., \& Checkel, J. T. (2015). Process Tracing: from metaphor to analytic tool. Cambridge: Cambridge University Press. https://doi.org/10.1017/CBO9781139858472

Bresser-Pereira, L. C. (2016). Reflecting on new developmentalism and classical developmentalism. Review of Keynesian Economics, 4(3), 331-352. https://doi.org/10.4337/roke.2016.03.07

Breul, M., \& Revilla Diez, J. (2018). An intermediate step to resource peripheries: The strategic coupling of gateway cities in the upstream oil and gas GPN. Geoforum, 92(March), 9-17. https://doi. org/10.1016/j.geoforum.2018.03.022

Coe, N. M., Dicken, P., \& Hess, M. (2008). Global production networks: Realizing the potential. Journal of Economic Geography, 8(3), 271-295. https://doi.org/10.1093/jeg/lbn002

Coe, N. M., Hess, M., Yeung, H. W., Dicken, P., \& Henderson, J. (2004). 'Globalizing' regional development: a global production networks perspective. Development, 468-484. https://doi. org/10.1111/j.0020-2754.2004.00142.x

Coe, N. M., \& Yeung, H. W.-C. (2015). Global Production Networks: Theorizing Economic Development in an Interconnecter World (1st ed.). Oxford: Oxford University Press.

Cohen, E., \& Franco, R. (1992). Evaluación de proyectos sociales. (Vol. 48). Mexico: Siglo XXI.

Cohen, W. M., \& Levinthal, D. A. (1990). Absorptive capacity: a new perspective on learning and innovation. Administrative Science Quarterly, 35(1), 128-152.

David, P. A. (2000). Path dependence, its critics and the quest for 'historical economics'. In Evolution and Path Dependence in Economic Ideas: Past and Present. MA: Edward Elgar.

Dicken, P. (2015). Global Shift (7th ed.). New York: The Guildord Press.

Edquist, C. (1997). EDQUIST, C. Systems of Innovation: Technologies, Institutions and Organizations. London: Pinter/Cassell Academic, 1997. https://doi.org/10.1016/S0024-6301(98)90244-8

Florida, R. (2011b). Cities and the Creative Class in Asia, (March), 1-2.

Freeman, C., \& Soete, L. (1997). Introduction. The economics of Industrial Innovation. 
Friedmann, J. \& Wolff, G. (1982). World city formation: an agenda for research and action. International Journal of Urban and Regional Research, 63(3), 309-344. https://doi.org/10.1111/j.1468-2427. 1982.tb00384.x

Henderson, J., Dicken, P., Hess, M., Coe, N., \& Wai-Chung Yeung, H. (2002). Global production networks and the analysis of economic development. Review of International Political Economy, 9(3), 436-464. https://doi.org/10.1080/09692290210150842

Hospers, G.-J. (2003). Creative cities: Breeding places in the knowledge economy. Knowledge, Technology \& Policy, 16(3), 143-162. https://doi.org/10.1007/s12130-003-1037-1

Knox, P. (1997). Globalization and Urban Economic Change. The Annals of the American Academy of Political and Social Science, 551, 17-27.

Lundvall, B.-A. (1992). National Systems of Innovation. Towards a Theory of Innovation and Interactive Learning. London: Pinter Publishers.

Mello, P. A. S. (2015). A arquitetura jurídico-institucional de uma ambiente de inovação brasileiro: $O$ Parque Tecnológico de São José dos Campos. Fundação Getulio Vargas.

Nelson, R. \& Rosenberg, N. (1993). NELSON, R.; ROSENBERG, N. National Innovation Systems. A Comparative Analysis. New York: Oxford University Press. https://doi.org/10.3319/ TAO.2002.13.1.39(T)C.-H.

Parnreiter, C. (2010). Global cities in Global Commodity Chains: Exploring the role of Mexico City in the geography of global economic governance. Global Networks, 10(1), 35-53. https://doi. org/10.1111/j.1471-0374.2010.00273.x

Parnreiter, C. (2015). Managing and governing commodity chains: The role of producer service firms in the secondary global city of Hamburg. Erde, 146(1), 1-15. https://doi.org/10.12854/erde-146-1

Pike, A., Rodríguez-Pose, A., \& Tomaney, J. (2011). Handbook of Local and Regional Development. New York: Routledge.

Rosenberg, N. (2006). Por dentro da caixa preta: tecnologia e economia. Por dentro da caixa-preta: tecnologia e economia. Editora Campinas.

Scholvin, S., Breul, M., Mello, P., Françoso, M., Hiratuka, C., Revilla, J., ... Hiratuka, C. (2017). Gateway cities in global production networks: Exemplified by the oil and gas sector (No. 307). Texto para discussao. Unicamp. IE, Campinas (Vol. 307).

Sigler, T. J. (2013). Relational cities: Doha, Panama City, and Dubai as 21st century entrepôts. Urban Geography, 34(5), 612-633. https://doi.org/10.1080/02723638.2013.778572

Steiner, J. E., Cassim, M. B., \& Robazzi, A. C. (2008). Parques Tecnológicos: Ambientes de Inovação. Revista IEA - USP.

Storper, M. (2013). Keys to the City How Economics, Institutions, Social Interaction, and Politics Shape Development. Oxford: Princeton University Press.

Tanner, A. N. (2005). Cities and the Creative Class. London: Routledge.

Turkina, E., Assche, A. Van, \& Kali, R. (2016). Structure and evolution of global cluster networks: Evidence from the aerospace industry. Journal of Economic Geography, 16(6), 1211-1234. https://doi.org/10.1093/jeg/lbw020

Venneson, P. (2008). Case studies and process tracing: theories and practices. In Approaches and Methodologies in Social Sciences: a pluralist perspective. (pp. 223-239). New York: Cambridge University Press. 